showed the need for merging our two cultures, the scientific and the literary. Of recent years, the nonscientific world seems to be assimilating quite successfully the simpler concepts of physics, but is still far behind in its grasp of the trends in the biological sciences. These Reith Lectures provide an example of the kind of thinking and talking that must be done if the more recent developments of biology and genetics are to win their proper place in the general education and the intellectual culture of our population.

J. D. NISBET

\section{BIOCHEMISTRY AND HEREDITY}

The Chemistry of Heredity

By Prof. Stephen Zamenhof. (Publication No. 365, American Lecture series. A Monograph on American Lectures in Living Chemistry.) Pp. xi+106. (Oxford : Blackwell Scientific Publications; Springfield, Ill. : Charles C. Thomas, 1959.) 34s. net.

THE great and diversified scientific effort which we are witnessing to-day all over the world has brought with it problems of communication. The expanding list of scientific journals bears witness to the volume of publications by which scientists are attempting to inform others of their discoveries. Such publications, however, may appeal only to like-minded specialists. Nevertheless, scientists of all disciplines as well as medical practitioners do, from time to time, feel the need to acquaint themselves with the state of knowledge in a particular field. Another, much larger, group of potential readers interested in the facts of scientific advance is the general public. Many of its members have helped to finance "the enlightened programs of research grants in our country" to which Prof. Zamenhof so rightly pays tribute in the dedication of his book. In the choice and presentation of the material of this monograph the author has apparently tried to aim at the professing scientists, the medical readers as well as the curious but unqualified.

In the introduction the author prepares the ground for the subsequent discussion of the possible mechanisms for the transmission of heredity by chemical compounds. Prof. Zamenhof then lists in outline required properties of heredity determinants and gives examples of classes of biological systems which must reasonably be under their genetic control. In the second chapter evidence is given for the central thesis of this book that heredity determinants are chemical substances. The non-specialist or even student is gently led towards the objective that deoxyribonucleic acid is the most plausible carrier of heredity. Due weight is here given to the direct proof for this postulate where viruses are concerned, which Prof. Zamenhof puts beside the almost incontrovertible but indirect evidence for the genetic role of deoxyribonucleic acid in higher organisms. A résumé of the structure of the nucleic acids is then followed by a discussion of the implications of those biochemical experiments by which nucleic acids have been synthesized in vitro. Under the heading "Mutation" the author regrettably only touches on hypotheses and on the genetic concept of carcinogenesis. Perhaps he wished to keep the account of work so close to his own promising field short for the sake of clarity. The facts of cytoplasmic inheritance are authoritatively stated and the subject well set within the context of the book. The remainder of this monograph is concerned with research in biochemical genetics: studies with micro-organisms and the examination of hereditary defects in man. The reader is given a hint of the problems, theoretical and practical, which confront investigators in this field.

This is a book that can be recommended to scientists and medical men who wish to widen their horizons, and to students providing they can persuade their library to buy it. The problem of how to present scientific facts, let alone the complexities of the chemistry of heredity, to the lay reader has not been brought closer to $a$ solution by this volume.

The book is well produced; misprints are practically absent, but the text gives examples of bizarre notions of how to divide words. The comprehensive bibliography should be useful to all readers alike. P. CoHN

\section{RECENT AMERICAN RESEARCH IN NEUROPSYCHIATRY}

Chemical and Molecular Basis of Nerve Activity By David Nachmansohn. Pp. xi+235. (New York : Academic Press, Inc.; London: Academic Press, Inc. (London), Ltd., 1959.) 7.50 dollars.

International Review of Neurobiology

Vol. 1. Edited by Carl C. Pfeiffer and John R. Smythies. Pp. xii +383 . (New York: Academic Press, Ine.; London: Academic Press, Inc. (London), Ltd., 1959.) 10 dollars.

Neuropharmacology

Transactions of the Fourth Conference, September 25, 26 and 27, 1957, Princeton, N.J. Edited by Harold A. Abramson. Pp. 285. (New York : Josiah Macy, Jr. Foundation, 1959.) 5 dollars.

THESE three books cover recent American researches on various aspects of the nervous system. The emphasis is on the nature of transmission, the chemical isolation of naturally occurring substances believed to have physiological or pathological importance, and the effects of drugs. In each case, the publishers are to be congratulated on having produced a handsome volume, well illustrated and carefully indexed. The bibliographies are satisfactory. With some qualifications, it may also be said that the authors, too, have given us something of which they may be proud.

Nachmansohn's book is the only monograph. It represents the results of nearly a quarter of a century's work by the author and colleagues on the metabolism of acetylcholine and its associated enzymes. It is a well-written, interesting, and coherent account of the progress which has been achieved. Beginning with a discussion of the physical events during nerveactivity, the author successively deals with a hypothesis of chemical transmission, the high speeds at which hydrolysis can take place, and substances which are capable of inhibiting the enzymes of this system. He goes on to describe the physicochemical exchanges in the electric organs of certain fish, and then makes a bold attempt to define in detail the role of acetylcholine in conduction. Here, there is a useful diagram to explain the author's views. The way in which nerve-gases, insecticides, and antidotes may be fitted into this scheme is next discussed. The book closes with chapters on the complex nature of the changes in the permeability of conducting membranes 